\title{
GENERATION-LOAD-STORAGE COOPERATIVE OPTIMIZATION SCHEDULING OF COMBINED HEAT AND POWER SYSTEM CONSIDERING WIND POWER UNCERTAINTY AND DEMAND RESPONSE
}

\author{
Ruiqing Lian ${ }^{1}$, Yiran $\mathrm{You}^{2}$, Yong $\mathrm{Li}^{3}$, Shiwei $\mathrm{Su}^{1}$ \\ ${ }^{1}$ College of Electrical Engineering \& New Energy, China Three Gorges University, \\ Yichang 443002, China \\ ${ }^{2}$ Quanzhou Power Supply Company of State Grid Fujian Electric Power Co., Ltd., \\ Quanzhou 362000, China, E-mail: yyr937@foxmail.com \\ ${ }^{3}$ Dawu Power Supply Company of State Grid Hubei Electric Power Co., Ltd., \\ Dawu 432800, China
}

The problem of wind power abandonment in the north areas of China is serious, which is mainly caused by the uncertainty of wind power and the "thermoelectric coupling" characteristics of cogeneration units. Aiming at this problem, this paper establishes the optimal scheduling model of generation-load-storage coordination in the electrothermal joint system with the goal of minimizing the amount of wind power discarded and the total scheduling cost of the system. Firstly, the responsive electrical and thermal loads on the demand side are divided into three types according to their types, namely, translatable, transferrable and reducible, and the demand response models are constructed to improve the fineness of the optimization on the demand side. Then, the scenario method is used to solve the uncertainty problem of wind power. Meanwhile, the influence of the energy storage side on system scheduling is considered. Finally, the results based on examples verify the effectiveness of the proposed model in promoting the absorptive of wind power and improving the overall economic benefit of the system. References 23, figures 8 , table 1 .

Key words: the uncertainty of wind power; generation-load-storage coordination optimization; optimized scheduling; wind power consumption; demand response.

1. Introduction. In recent years, renewable energy such as wind power has developed rapidly in China. However, with the gradual increase of wind power penetration in the power system, the problem of wind abandonment is prominent nationwide, especially in northern China, which has become an important factor limiting the development of wind power [1-3]. There are two reasons for the wind abandoning problem in northern China. One is the uncertainty of wind power output and the influence of reverse peak regulation characteristics. Second, the system scheduling is limited by the operation mode and thermoelectric coupling characteristics of CHP (Combined Heat and Power) units in northern China. Therefore, how to deal with wind power uncertainty and reverse peak regulation characteristics, as well as how to solve the thermoelectric coupling problem of CHP units are the key to solve the wind abandonment problem in northern China.

In view of the problem of wind abandonment in northern China, some scholars at home and abroad propose to add energy storage devices or electric boilers at the generation side to realize "thermoelectric decoupling", and preliminary results have been achieved. The authors [4-6] are not only limited to the power system level, but also improve the energy allocation capacity of the electric-thermal combined system by adding heat storage devices. The authors [7-8] studied the influence of heat storage devices at different locations on the wind abandonment rate and economy of the system. In [9], combined with the characteristics of regional energy structure in northern China, wind power heating was added as a dispatchable resource on the heat load side on the basis of heat storage to enhance the flexibility of the system.

According to the above research, the electric boiler and energy storage device have a certain positive effect on the decoupling of CHP unit and the consumption of wind power. However, there are still many key technologies to be broken through, especially the research and development of the storage device. Its installation capacity is limited, and the overall economic improvement of the system is not significant. Therefore, at present many scholars are conducting researches on the load side, hoping to improve the flexibility of the system and the consumption space of wind power by optimizing the load curve.

The authors [10-12] divide responsive electrical loads into three categories: reducible, transferable and translatable. Interactive load models are established respectively, which adjust the electrical load curve and realize the economic operation of the system. The authors [13-14] establishe a demand response model based on electricity price, build the elastic demand relationship between electricity consumption and price, and guide users through time-of-use electricity price to optimize the load curve. The authors [15] consider

(C) Ruiqing Lian, Yiran You, Yong Li, Shiwei Su, 2021 
the electro-thermal coupling relationship while considering the demand response of electric load, giving full play to the role of demand response in the electro-thermal combined system.

On the basis of energy storage equipment, the above literature added research on the demand side, which improved the consumption of wind power and the economic benefits of the system to a certain extent, but there are still some shortcomings. Firstly, most of its demand response only considers electrical load, without considering the role of thermal load response in the system. Secondly, its demand response strategy mostly adopts the mode of interruptible load or direct control, without considering different types of responsive electric and thermal load response models, and the planning is not detailed enough. Finally, they only consider the influence of one or both parties of generation, load and storage, which can no longer meet the current requirements of wind power consumption and economic benefits.

Therefore, this paper aims at minimizing the amount of abandoned air and the total scheduling cost of the system, and adds consideration to the generation and load side on the basis of the combined system with storage, electricity and heat. In addition to constructing demand response models for different types of electrical loads, the construction of demand response models for thermal loads is also considered. The scenario method is used to deal with the uncertainties of generation-side wind power, and a coordinated optimization scheduling model for generation-load-storage of an electric-thermal integrated system is established. Finally, the simulation results based on the constructed examples show that the proposed method and model can effectively improve the consumption of wind power and the system economy.

2. System structure and principle of CHP unit containing storage.

2.1. Generation-load-storage coordination optimal scheduling system architecture. The combined electric and thermal system studied in this paper is mainly composed of wind power unit, conventional thermal power unit, CHP unit, thermal energy storage device, electrical load and thermal load.

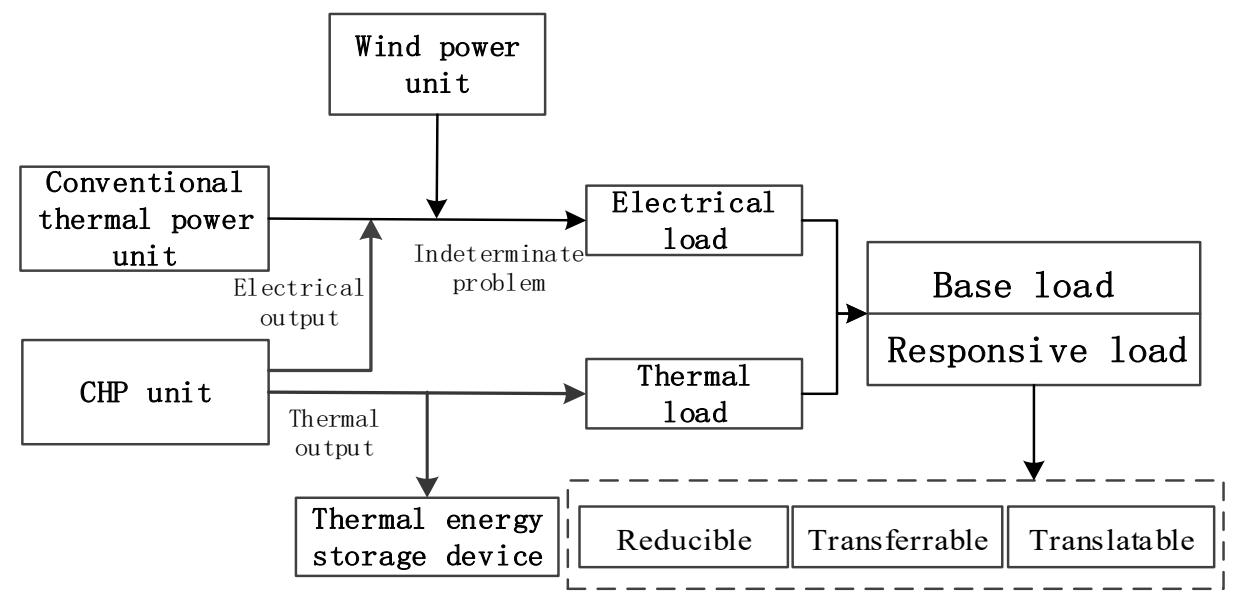

Fig. 1

Fig. 1 shows the structure diagram of generation-load-storage coordinated optimal dispatching system, which adds the consideration of wind power uncertainty on the basis of the combined system with storage, electricity and heat, and models the electric and heat loads on the load side respectively according to the type to adjust the load curve. Through coordination and optimization of generation-load-storage, it can provide more space for absorbing new energy while improving system economy.

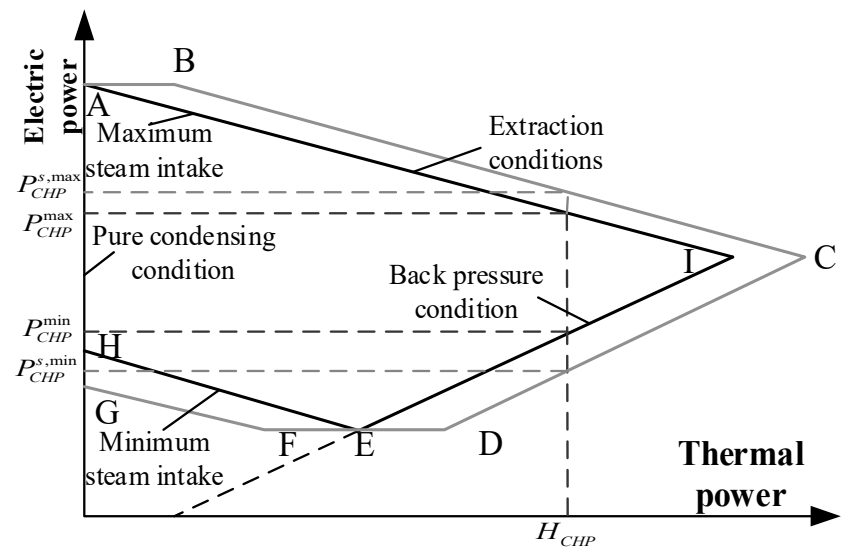

Fig. 2
2.2. Electrothermal characteristic curve of CHP unit with heat storage. The electrothermal characteristic curve of CHP unit with heat storage is shown in Fig. 2. AIEH is the operating range of extraction steam CHP, IE is the operating range of the back-pressure CHP unit. When the thermal output of CHP unit is $H_{C H P}$, the electric output of back pressure CHP unit is $P_{C H P}^{\min }$, the power output of extraction-steam CHP unit is interval $\left[P_{C H P}^{\min }, P_{C H P}^{\max }\right]$. Therefore, the extraction-steam CHP unit has higher flexibility, but it is still limited by the operation 
mode of "determined by heat", and cannot fully absorb new energy.

After adding the heat storage device, the operation interval of the extraction steam CHP unit is increased to $\mathrm{ABCDEFG}$, where $\mathrm{ABCDEI}$ is the heat release interval of the heat storage device and $\mathrm{HEFG}$ is the heat storage area of the energy storage device. As can be seen from Fig. 2, the addition of heat storage device expands the power output adjustment range of extractable CHP unit and significantly improves the flexibility of the system.

\section{Demand response and wind power uncertainty treatment.}

3.1. Demand response model. In this paper, on the basis of flexible and responsive electric heating load, the models are divided into three types according to their respective characteristics, so as to improve the accuracy of the scheduling model.

1) Translatable load refers to the uninterruptible and integral translation of the responsive electric heating load [16]. The scheduling time interval in this paper is 1 hour, so in order to ensure the continuous load, the formula as follow should be satisfied:

$$
\left\{\begin{array}{l}
\sum_{t=\tau_{p}}^{\tau_{p}+t_{p}-1} \alpha_{p}=t_{p} \\
\sum_{t=\tau_{h}}^{\tau_{h}+t_{h}-1} \alpha_{h}=t_{h}
\end{array},\right.
$$

where $\tau_{h}$ and $\tau_{p}$ are the starting time of the time interval of thermal and electrical load after translation respectively; $t_{h}$ and $t_{p}$ are the durations of translational heat and electrical loads respectively; $\alpha_{h}$ and $\alpha_{p}$ are 0 1 state variables of whether the thermoelectric load is translated, and 1 represents load translation.

2) Transferable load refers to the responsive electric heating load with continuity constraints. The required electric energy remains unchanged before and after the electric heating load is transferred, and shall meet the following formula:

$$
\left\{\begin{array}{l}
\sum_{t=1}^{T}\left(P_{g l t}^{\mathrm{trans}}-P_{g t}^{\mathrm{rtans}}\right)=0 \\
\sum_{t=1}^{T}\left(P_{h l t}^{\mathrm{trans}}-P_{h t}^{\mathrm{rans}}\right)=0
\end{array},\right.
$$

where $P_{g l t}^{\text {trans }}$ and $P_{g t}^{\text {trans }}$ are transferable electric load power before and after dispatching; $P_{h l t}^{\text {trans }}$ and $P_{h t}^{\text {trans }}$ are transferable heat load power before and after dispatching.

3) Reducible load refers to the responsive electric heating load that can be reduced under the condition of meeting the needs of users. The electric heating load after reduction is expressed as:

$$
\left\{\begin{array}{l}
P_{g t}^{\mathrm{cut}}=\left(1-\beta_{p}\right) P_{g l t}^{\mathrm{cut}} \\
P_{h t}^{\mathrm{cut}}=\left(1-\beta_{h}\right) P_{h l t}^{\mathrm{cut}}
\end{array},\right.
$$

where $P_{g l t}^{\text {cut }}$ and $P_{h l t}^{\text {cut }}$ are the electric heating load before cutting at time t; $\beta_{p}$ and $\beta_{h}$ are the proportion of electric heating load reduced, and $0 \leq\left(\beta_{p}, \beta_{h}\right) \leq 1$.

3.2. Uncertainty treatment of wind power. Scenario method simulates the output uncertainty of wind power by generating a large number of wind power scenarios. The prediction error of wind power is assumed to follow the normal distribution with the mean value of 0 , which is $\Delta P_{w t} \sim N\left(0, \delta_{w t}{ }^{2}\right)$. Based on the wind power output forecast data of a typical day, Latin Hypercube Sampling (LHS) is used to generate the scene. The steps are as follows:

1) Samples to generate. Suppose that $\left[P_{w 1}, P_{w 2} \ldots \ldots P_{w T}\right]$ is an independent random variable of wind power output under a scheduling period, and $P_{w t}$ is a random variable at time $t$, and its cumulative probability distribution function is $Y_{t}=F_{t}\left(P_{w t}\right)$. Then, during sampling, the interval of cumulative probability distribution function $[0,1]$ at each scheduling time is first divided into $M$ equal parts, and the median value of each subinterval is selected. Then the inverse transformation of the cumulative probability distribution function is used to get the sampling value, that is, the output of wind power. Finally, a typical daily wind power output matrix of $M \times T$ is obtained.

2) Sorting. When sampling values are used to simulate wind power uncertainty, there is always correlation between the sampled data of random variables, which will affect the accuracy of the simulation. Therefore, Cholesky decomposition method is needed to be used for sorting to eliminate the correlation and 
improve the accuracy of the simulation.

The generated rank correlation coefficient matrix $\rho_{w}$ of the $M \times T$ wind power output matrix and the rank correlation coefficient matrix $\rho_{L}$ of the $M \times T$ sequence matrix L are calculated. Cholesky decomposition of $\rho_{w}$ and $\rho_{L}$ :

$$
\rho_{L}=B B^{T}, \rho_{w}=D D^{T}, Q_{L}=B^{-1} L, Q_{w}=D Q_{L},
$$

where matrices $B$ and $D$ are lower triangular matrices.

After this transformation, the original generated $M \times T$ wind power output matrix can be arranged according to the order of the elements of matrix $Q_{W}$ to maintain the same correlation between the sample matrix and the random variable.

3) Scene reduction. The sample matrix obtained through LHS has a large amount of data, which will increase the amount of calculation and reduce the efficiency of solution in the actual calculation process. Therefore, a few specific scenes need to be selected to represent the overall scene. Therefore, this paper based on SBR method to reduce the scene, specific steps can be found in literature [17].

4. Generation-load-storage optimization scheduling model for electric and thermal systems.

4.1. The objective function. In this paper, the objective function is to minimize the penalty cost of wind abandonment and the total dispatching cost of the system, and comprehensively consider the generation cost of conventional thermal power unit, the generation cost of CHP unit, the operation and maintenance cost of heat storage device, the penalty cost of wind abandonment and the demand response cost. The mathematical expression is as follows:

$$
\min C_{z}=C_{D}\left(P_{G i t}\right)+C_{S}\left(P_{S, \text { store }}, P_{S, \text { release }}\right)+C_{H}\left(P_{H j t}\right)+C_{W}\left(P_{W t}^{q}\right)+C_{R}\left(P_{R t}\right),
$$

where $C_{Z}$ is the total scheduling cost of the system, $C_{D}$ is the generating cost of conventional thermal power unit, $C_{H}$ is the power generation cost of CHP unit, $C_{S}$ is the operation and maintenance cost of the heat storage device, $C_{W}$ is the penalty cost of wind abandonment, $C_{R}$ is the demand response cost, $P_{G i t}$ is the electric output of the No. $i$ conventional thermal power unit at time $t, P_{H j t}$ is the conversion output of the No. $j \mathrm{CHP}$ unit at time $t, P_{S \text {,store }}(t)$ and $P_{S, \text { release }}(t)$ are the heat storage and release power of the heat storage device, $P_{W t}^{q}$ is the actual amount of wind power online at time $t, P_{R t}$ is the total load that is reduced, transferred and translated at the time $t$.

1) The cost of power generation of conventional thermal power units. In general, the cost utility of thermal power units mainly considers the operation cost and the start-up and shutdown cost, and the general form of its cost utility function is as follows:

$$
C_{D}\left(P_{G i t}\right)=\sum_{t=1}^{T} \sum_{i=1}^{N_{G}}\left[\begin{array}{l}
Q_{G i t}\left(1-Q_{G i(t-1)}\right) \cdot \tau_{G i t}+ \\
Q_{G i t} \cdot R_{G i t}\left(P_{G i t}\right)
\end{array}\right],
$$

where the specific mathematical expression of operating $\operatorname{cost} R_{G i t}\left(P_{G i t}\right)$ is as follows:

$$
R_{\text {Git }}\left(P_{\text {Git }}\right)=a_{i}+b_{i} P_{G i t}+c_{i} P_{\text {Git }}^{2} .
$$

In the formula, $Q_{G i t}$ and $Q_{G i(t-I)}$ respectively represent the start-stop state of Unit $i$ at time periods $t$ and $t-1,0$ represents shutdown and 1 represents startup, $N_{G}$ represents the total number of thermal power units participating in dispatching, $T$ represents the scheduling period, $\tau_{G i t}$ stands for the start-stop cost of the thermal power units, $R_{G i t}\left(P_{G i t}\right)$ represents the operating cost of thermal power units, $a_{i}, b_{i}$ and $c_{i}$ are the operating cost parameters of the unit.

2) Power generation cost of CHP unit. In the system studied in this paper, the heat load is set to be supplied by the heat generated by the operation of CHP unit. Therefore, CHP unit will operate without shutdown, and the impact of CHP unit start-up and shutdown will not be considered, only its operation cost will be considered [18]. Its expression is as follows:

$$
C_{D}\left(P_{G i t}\right)=\sum_{t=1}^{T} \sum_{j=1}^{N_{H}}\left(a_{j} P_{H j t}^{2}+b_{j} P_{H i t}+c_{j}\right)
$$

where $N_{H}$ is the number of CHP units, $a_{j}, b_{j}$ and $c_{j}$ are operating cost parameters of CHP unit respectively.

In order to deal with the operation cost of extraction steam CHP unit, the electrical and thermal power under the extraction steam condition should be converted to the pure condensing condition for calculation. The conversion expression is as follows:

$$
P_{H j t}=P_{g i t}+|k| P_{h j t},
$$


where $P_{g j t}$ and $P_{h j t}$ are the electrical and thermal power values of the No. $j$ CHP unit at time $t, k$ is the slope of the thermoelectric characteristic curve of the CHP unit under the steam extraction condition.

3) Operation and maintenance cost of heat storage device.

In general, the operation and maintenance costs of heat storage devices are related to their heat storage and release characteristics. The following formula is the heat storage and release characteristics of the heat storage device

$$
H_{S}(t)=H_{S}(t-1)+\left(\eta_{S, \text { store }} P_{S, \text { store }}(t)-P_{S, \text { release }}(t) / \eta_{S \text {,release }}\right) \Delta t, t \geq 2,
$$

where $H_{S}(t)$ and $H_{S}(t-1)$ are the heat storage of the heat storage device at time $t$ and $t-1$, when the heat input and output are zero, the physical meaning is that the heat stored does not change [19]. The $\eta_{S \text {,store }}$ and $\eta_{S \text {,release }}$ are the heat storage and release efficiency of the heat storage device at time $t$. Therefore, the operation and maintenance cost of the heat storage device can be expressed as follows:

$$
C_{S}\left(P_{H j i t}\right)=c_{s}\left|P_{S, \text { store }}(t)-P_{S, \text { release }}(t)\right| \text {, }
$$

where $c_{s}$ is the unit operation and maintenance cost of the heat storage device. Thus, combined with the formulas (8-11), the operating cost of CHP unit containing storage can be rewritten as

$$
C_{D}\left(P_{G i t}\right)=\sum_{t=1}^{T} \sum_{j=1}^{N_{H}}\left[\begin{array}{l}
a_{j}\left(P_{g i t}+|k|\left(P_{h j t}+P_{S}(t)\right)^{2}\right)+ \\
b_{j}\left(P_{g i t}+|k|\left(P_{h j t}+P_{S}(t)\right)\right)+c_{j}
\end{array}\right] .
$$

According to formula (12), thermal power output, charging and releasing heat plan and CHP unit's own characteristics will affect the power generation cost of the unit.

4) Wind abandonment penalty costs and demand response costs. The formulas (13-14) are the penalty cost of wind abandonment and the cost of demand response

$$
\begin{aligned}
& C_{W}\left(P_{W t}^{q}\right)=c_{q} \sum_{t=1}^{T}\left(\left|P_{w t, \text { real }}-P_{w t}^{q}\right|\right), \\
& C_{R}\left(P_{R t}\right)=c_{r \zeta} \sum_{\zeta=1}^{3} \sum_{t=1}^{T} P_{R \zeta t},
\end{aligned}
$$

where $P_{w t, \text { real }}$ is the actual wind power of wind power at time $t, c_{q}$ and $c_{r \xi}$ are unit wind abandonment costs and unit demand response costs of different types of loads respectively.

\subsection{The constraint.}

1) Power system constraint. Electrical power balance constraints:

$$
\sum_{i=1}^{N_{G}} P_{G i t}+\sum_{j=1}^{N_{H}} P_{g i t}+P_{w t}=P_{g l t}+\Delta P_{g l t}
$$

where $P_{g l t}$ is the system load at time $t, \Delta P_{g l t}$ is the load offset generated by the demand response at time $t$. Positive value means increased load and negative value means reduced load.

In addition to power balance constraints, power system constraints also include wind power output constraints, thermal power unit output constraints, thermal power unit climbing constraints, thermal power unit outage and start-up output constraints, and positive and negative rotation reserve constraints, which have been a lot of literature research will not be repeated here [20-23].

2) Thermodynamic system constraints. Thermal power balance constraints:

$$
\sum_{j=1}^{N_{H}} P_{h j t}+P_{S, \text { release }}(t)=P_{h l t}+\Delta P_{h l t}+P_{S, \text { store }}(t),
$$

where $P_{h l t}$ is the heat load before the demand response at time $t$, and $\Delta P h l t$ is the change of thermal load after demand response at time $t$.

Constraint of heat storage device:

$$
\left\{\begin{array}{l}
P_{S, \text { store }}(t) \leq P_{S, \text { store }}^{\max } \\
P_{S, \text { release }}(t) \leq P_{S, \text { release }}^{\max }, \\
H_{S}(t) \leq H_{S}^{\max }
\end{array}\right.
$$

where $P_{S, \text { store }}^{\max }, P_{S, \text { release }}^{\max }$ and $H_{S}^{\max }$ respectively represent the maximum heat storage and release power of the heat storage device and the maximum heat storage of the heat storage device.

In addition to the above constraints, thermodynamic system constraints also include CHP unit output constraints and CHP unit climbing constraints, which are similar to the constraints of thermal power units. 
Thermal output should be equivalent to electrical output, and the equivalent process is shown in the formula (9).

3) Demand response constraints. In the established responsive load model, in addition to the formulas (1-3), the transferable electric heating load needs to meet the following constraints.

Transferable interval constraints:

$$
t \in\left[t_{t}^{t r-}, t_{t}^{t r+}\right]
$$

Minimum duration constraint:

$$
\begin{aligned}
& \sum_{\tau=t}^{t+t_{\text {ming }}^{\text {trans }}-1} v_{\tau} \geq t_{\min }^{\mathrm{trans}}\left(v_{t}-v_{t-1}\right) \\
& t=t_{t r-}, t_{t r-}+1, \cdots t_{t r+}-t_{\min }^{\mathrm{trans}}+1
\end{aligned}
$$

where $t_{t}^{t r-}$ and $t_{t}^{t r+}$ are the upper and lower limits of the interval where load transfer can be allowed, $t_{\min }^{\text {trans }}$ is the minimum continuous running time, $v_{t}$ is the $0-1$ state variable to determine whether the load is transferred, $v_{t}=1$ means that the load is transferred at time $t$.

\section{Generation-load-storage optimization scheduling model for electric and thermal systems.}

5.1. The example designs. The model established in this paper is a mixed problem, so the more mature commercial solvers YALMIP and CPLEX are used to solve the problem. The "source" of the calculation example of the established electric-thermal combined system consists of four conventional thermal power units, two CHP units and one wind power unit. The power of the wind power unit is 50MW, and the specific parameters of the unit are referred to Literature [13]. The "storage" side of the system is composed of a heat storage device with a transmission power of $100 \mathrm{MW}$ and a capacity of $1000 \mathrm{MW}$. The system scheduling cycle is 24 hours, and the unit scheduling period is 1 hour. A typical day was selected as the research object in this paper to simplify the comparison. When the uncertainty of wind power is not considered, the wind power output is set at $20 \mathrm{MW}$, in which the unit heat storage operation and maintenance cost is $0.01 \mathrm{CNY} / \mathrm{kW}$, and the unit wind abandonment penalty cost is $0.2 \mathrm{CNY} / \mathrm{kW}$.

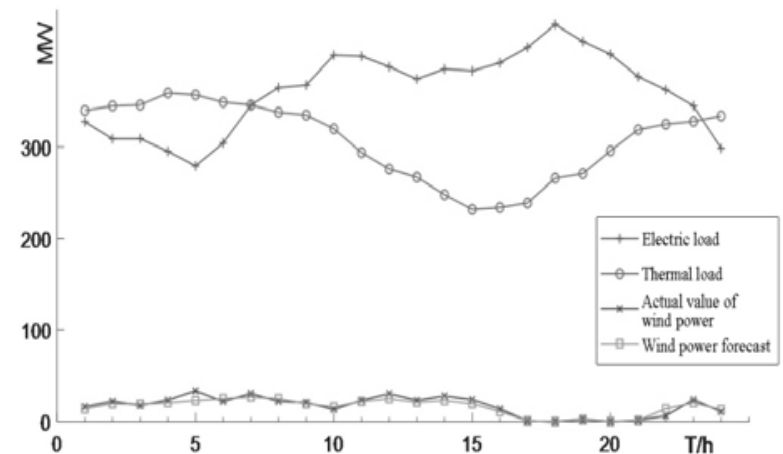

Fig. 3

Fig. 3 shows the electric heating load curve, the actual wind power curve of the typical day and the wind power prediction curve after the uncertainty treatment of the scenario method. Electrical and thermal loads before optimization are shown in Fig. 4, in which the left figure is the electrical load and the right figure is the thermal load. The electric heating load can be reduced mainly for residential heat and lighting electricity. The transferable electrical load is mainly household electricity. Translatable electric loads are mainly for electric vehicles. Transferable and translational heat loads are mainly used in production.

In the calculation example, the demand response prices of the electric heating load that can be reduced, transferred and translated are $0.03,0.02$ and $0.01 \mathrm{CNY} / \mathrm{kW}$ respectively.
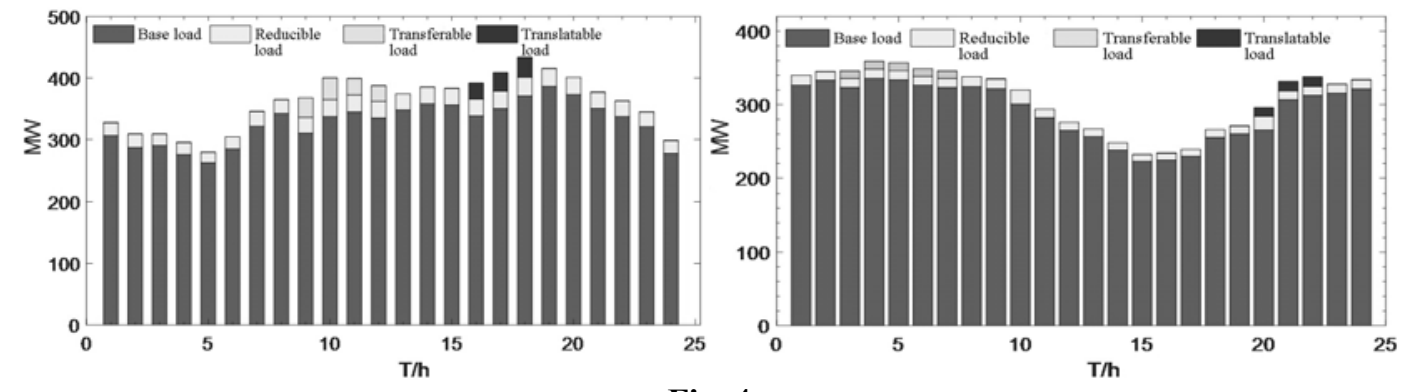

Fig. 4

5.2. Optimization result analysis. The model and method established in this paper are used to optimize the calculation example, and the optimization results are as follows. 
Fig. 5 shows the electrical and thermal loads of each type after optimization in which the left figure is the electrical load and the right figure is the thermal load. By comparison with Fig. 4, it can be seen that the trough of heat load is just the peak of electricity consumption. If the operation mode of "setting power by heat" is adopted, the scheduling is not flexible enough due to the coupling of thermoelectric units. However, after considering the side response of electric and thermal loads, the electrical loads in periods 16-18 are shifted to periods 4-6, and the loads in periods 9-12 are transferred to other periods of low electric loads, smoothing the electric load curve and alleviating the impact of electric and thermal coupling. Compared with electric load, the main reduction period of heat load is the trough period of heat load. However, due to the existence of heat storage devices, the cost of heat storage and release is lower than that of demand response, so the reduction amount of heat load is not much. The thermal load is mainly transferred to period $0-12$, and the translational thermal load is transferred from period 20-22 to period 13-15.
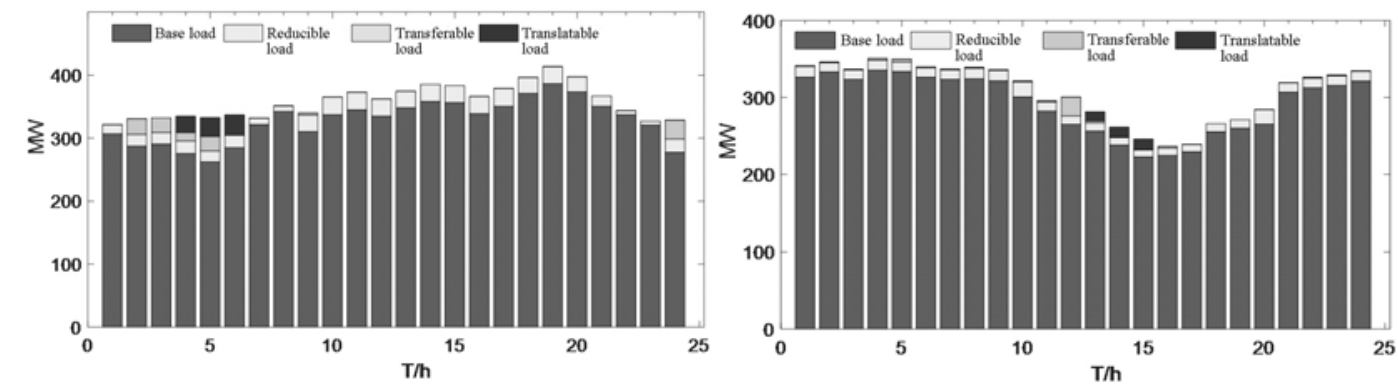

Fig. 5

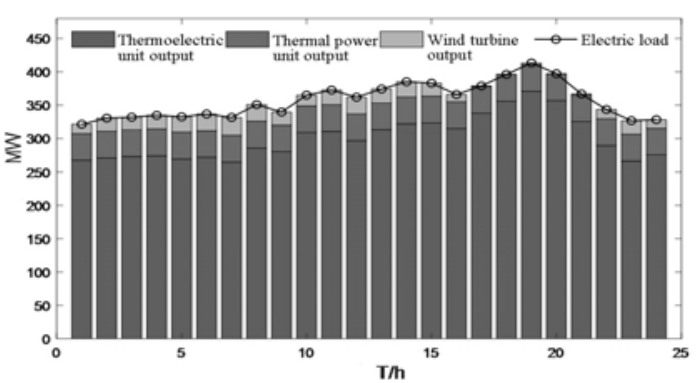

Fig. 6

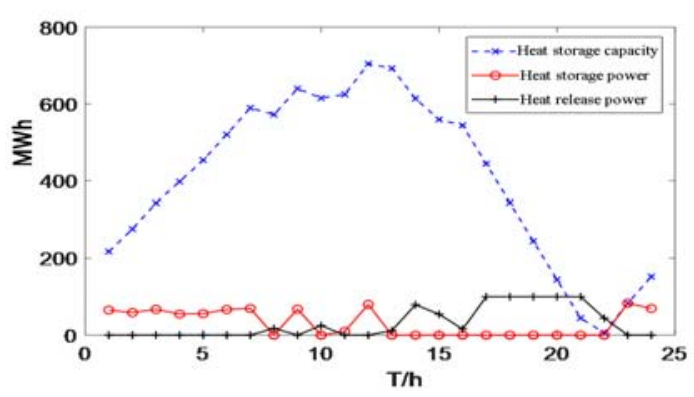

Fig. 7

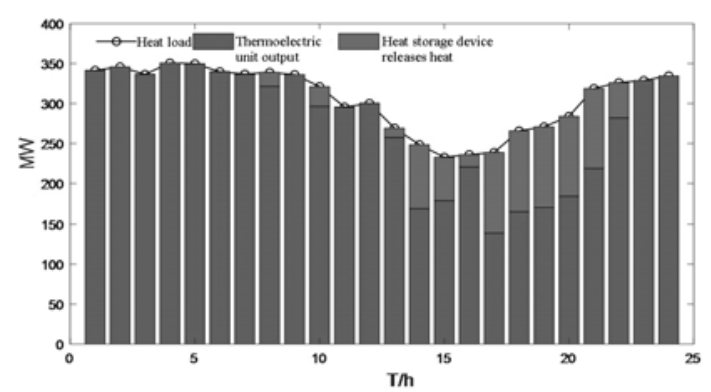

Fig. 8

In Fig. 6 the schematic diagram of the power output of each unit in the optimized system is shown. It can be seen from the figure that the system meets the electric power balance, and the power output of the thermoelectric unit is much higher than that of the thermal power unit. The main reason is that CHP unit has higher energy utilization rate and lower fuel cost compared with the thermal power unit. The operation of the heat storage device and the heat output of the system are shown in Fig. 7 and Fig. 8.

According to Fig. 7 and Fig. 8, the thermal power balance of the system is satisfied, and the heat storage of the heat storage device remains unchanged within a scheduling cycle. By comparing Fig. 5, it can be seen that the main heat release period is concentrated in period 14-22, namely the peak period of electrical load. Due to the existence of electrothermal coupling, the output electric power of CHP unit is limited in order to meet the thermal demand in the peak period of electricity, and the thermal power deficit needs to be provided by the thermal power unit. However, the fuel cost of the thermal power unit is high, so the heat output of CHP unit needs to be reduced, and the heat storage device can release heat to provide the thermal power deficit and reduce the operating cost of the system.

From the analysis of results, it can be seen that the "storage" and "load" of the system will influence each other in the process of optimal scheduling. Therefore, it is necessary to consider the coordination and optimal scheduling among generation, load and storage to optimize the economy of the system.

5.3. Comparison and analysis. In order to verify the effectiveness of the optimal dispatching method based on the coordination of generation, load and storage and the 
influence of wind power on system economy and wind abandonment absorption, the following three scenarios are selected for analysis. Since the influence of energy storage on system economy has been verified in many papers, a comparative study will not be conducted here.

Scenario 1: The system considers the electro-thermal load response and energy storage, without considering the uncertainty of wind power. Scenario 2: The system considers wind power uncertainty and energy storage, but does not consider the response of electrothermal load. Scenario 3: The system considers the electro-thermal load response and energy storage, as well as the uncertainty of wind power, namely the model established in this paper. Comparison of system costs under three scenarios is shown in Table.

\begin{tabular}{cccc}
\hline Index & Scenario 1 & Scenario 2 & Scenario 3 \\
\hline Generating cost of thermoelectric unit & CNY 114,800 & CNY 126,200 & CNY 116,700 \\
Costs of thermal power generating units & CNY 11,500 & CNY 14,900 & CNY 14,300 \\
Operating cost of heat storage device & CNY 7,300 & CNY 8,100 & CNY 7,400 \\
Demand response cost & CNY 8,300 & - & CNY 7,900 \\
Wind abandonment penalty costs & CNY 40,700 & CNY 16,800 & CNY 14,600 \\
Total system cost & CNY 182,600 & CNY 166,000 & CNY 160,900 \\
Abandon the wind rate & $16.48 \%$ & $16.09 \%$ & $12.16 \%$ \\
\hline
\end{tabular}

According to the data in Table, under different emphases, there are slight differences in the costs of systems in the three scenarios. Due to the consideration of the demand side response in Scenario 1 and Scenario 3 and the optimization of the electric heating load curve, the generation cost of thermal power and CHP units is greatly reduced, compared with Scenario 2, the generation cost of thermal power unit is reduced by CNY 3,400 and CNY 600 respectively, and that of CHP unit is reduced by CNY 11,400 and CNY 9,500 respectively. Scenario 1 does not consider the uncertainty of wind power, and the penalty cost of wind abandonment is CNY 40,700. This cost not only includes the penalty of wind abandonment, but also includes the penalty cost of the burden of system scheduling caused by incorrect wind power prediction. In scenario 2 and scenario 3, the uncertainty of wind power is taken into account, and the penalty cost of wind abandonment is CNY 16,800 and CNY 14,600 respectively. The penalty cost of wind abandonment in Scenario 2 and 3 is obviously less than that in Scenario 1, which indicates that considering the influence of wind power uncertainty in the optimization dispatching process can significantly improve the system economy. However, the penalty cost of wind abandonment in Scenario 2 is CNY 2,200 higher than Scenario 3 , indicating that the change of electric and heating load curve affects the output plan of wind turbine. It also reflects the mutual influence of generation-load-storage in the process of system optimization dispatching. Therefore, a comprehensive consideration should be taken to improve the overall economy of the system.

Finally, the total scheduling cost of the system in Scenario 3 is CNY 160,900. Compared with Scenario 1 and 2, the total dispatching cost of the system is reduced by CNY 21,700 and CNY 5,100 respectively, and the wind abandonment rate in Scenario 3 is $12.16 \%$, which is lower than that in Scenario 1 and 2. The results show that the method proposed in this paper has good system economy and high wind power consumption rate, and can provide effective technical support and reference for the production and management of combined electric and thermal system.

6. Conclusions. In this paper, with the goal of minimizing the total dispatching cost of the system, an optimal dispatching model of source-load-storage coordination was established based on the combined system with storage, electricity and heat, and the influence of wind power uncertainty and demand response was considered. The optimization results and comparison results are analyzed in detail, and the results show that:

1) The problem of wind abandonment is not only caused by the lack of flexibility of the system, and it is not comprehensive to analyze the electro-thermal coupling problem of CHP unit only. At the same time, considering the uncertainty of wind power can not only further reduce the amount of wind abandonment, but also improve the economy of the system.

2) In this paper, electrical and thermal load responses are considered in the load-side demand response, and they are classified and modeled according to their characteristics. Through the demand-side response, the electric and thermal load curve is optimized, the output of the unit on the generation side is improved, and the interaction between the generation and the load is realized. In addition, the energy storage device increases the flexibility of the unit. The heat release from the heat storage device provides the thermal power gap, reduces the operating cost of the system, and realizes the interaction of storage and charge. 
Therefore, in the optimization scheduling process of the electrothermal combined system, generation-loadstorage influence and restrict each other, and it is very necessary to comprehensively study these three aspects compared with unilateral or two-sided studies.

3) In this paper, a coordinated optimization dispatching model of generation-load-storage is established for the combined electric and thermal system. The numerical example analysis proves the effectiveness of the model presented in this paper, which achieves a higher wind power consumption rate and a lower system scheduling cost.

Acknowledgement. This work was supported in part by the National Natural Science Foundation of China (61876097), Hubei Key Laboratory of Cascaded Hydropower Station Operation Foundation (2019KJX10).

1. Zeng M., Yang Y., Liu D., Zeng B., Ouyang S., Lin H., Han X.. Generation-grid-load-storage coordinative optimal operation mode of energy internet and key technologies. Power System Technology. 2016. No 1. Pp. 114-124.

2. Bie Z., Wang X., Hu Y. Review and Prospect of Planning of Energy Internet. Proceedings of the Chinese Society of Electrical Engineering. 2017. No 22. Pp. 6445-6462.

3. Yi Z., Li Z. Combined Heat and Power Dispatching Strategy Considering Heat Storage Characteristics of Heating Network and Thermal Inertia in Heating Area. Power System Technology. 2018. No 5. Pp. 1378-1384.

4. $\quad$ Xu F., Min Y., Chen L., Chen Q., Hu W., Zhang W., Wang X., Hou Y. Combined electricity-heat operation system containing large capacity thermal energy storage. Proceedings of the Chinese Society of Electrical Engineering. 2014. No 29. Pp. 5063-5072.

5. $\quad$ Li Z., Zhang F., Liang J., Yun Z., Zhang J. Optimization on microgrid with combined heat and power system. Proceedings of the Chinese Society of Electrical Engineering. 2015. No 14. Pp. 3569-3576.

6. Pinson P., Girard R. Evaluating the quality of scenarios of short-term wind power generation. Applied Energy. 2012. Pp. 12-20.

7. $\quad$ Cui Y., Chen Z., Yan G., Tang Y. Coordinated wind power accommodating dispatch model based on electric boiler and CHP with thermal energy storage. Proceedings of the Chinese Society of Electrical Engineering. 2016. No 15. Pp. 4072-4080.

8. Yao Y. A Method for allocation heat storage capacity of concentration solar power considering scheduling economy. Acta Energiae Solaris Sinica. 2019. No 11. Pp. 3039-3045.

9. Yuan G., Wang L., Wang B. Optimal Dispatch of Heat-Power Load and Economy Benefit Analysis Based on Decoupling of Heat and Power of Virtual Power Plant. Proceedings of the Chinese Society of Electrical Engineering. 2017. No 17. Pp. 4974-4985. DOI: https://doi.org/10.13334/j.0258-8013.pcsee.161300

10. Sun C., Wang L., Xu H. An interaction load model and its application in microgrid day-ahead economic scheduling. Power System Technology. 2016. No 7. Pp. 2009-2015.

11. Bahramirad S., Reder W., Khodaei, Reliability-constrained optimal sizing of energy storage system in a microgrid. IEEE Transactions on Smart Grid. 2012. No 4. Pp. 2056-2062.

12. Kinhekar N., Padhy N.P., Gupta H.O. Multiobjective demand side management solutions for utilities with peak demand deficit. International Journal of Electrical Power and Energy Systems. 2014. Vol. 55. Pp. 612-619.

13. Liu X., Zhang F., Sun Q., Zhong W. Multi-Objective Optimization Strategy of Integrated Electric-Heat System Based on Energy Storage Situation Division. IEEE Access. 2021. Pp. 19004-19024.

14. Hemmati M., Mirzaei M.A., Abapour M., Zare K. Economic-environmental analysis of combined heat and power-based reconfigurable microgrid integrated with multiple energy storage and demand response program. Sustainable Cities and Society. 2021. Vol. 69. 102790. DOI: https://doi.org/10.1016/j.scs.2021.102790

15. Liu T., Lu J., He C., Xie Y. Day-ahead economic dispatch of multi-energy parks considering integrated thermo-electric demand response and high penetration of renewable energy. Electric Power Automation Equipment. 2019. No 8. Pp. 261-268.

16. Xu Z., Sun Y., Xie D., Wang J. Optimal Configuration of Energy Storage for Integrated Region Energy System Considering Power Thermal Flexible Load. Automation of Electric Power Systems. 2020. No 2. Pp. 53-59.

17. Wang J., Xu J., Liao S., Sima L., Sun Y., Wei C.,Coordinated Optimization of Integrated Electricity-Gas Energy System Considering Uncertainty of Renewable Energy Output. Automation of Electric Power Systems. 2019. No 15. Pp. 2-9.

18. Cui Y., Yang Z., Zhong W., Ye X. A Joint Scheduling Strategy of CHP With Thermal Energy Storage and Wind Power to Reduce Sulfur and Nitrate Emission. Power System Technology. 2018. No 4. Pp. 1063-1070.

19. Zhai Q., Zhou Y., Li X., Wu J., Xu Z., Xie X. Nonanticipativity and All-Scenario-Feasibility: State of the Art, Challenges, and Future in Dealing with the Uncertain Load and Renewable Energy. Proceedings of the Chinese Society of Electrical Engineering. 2020. No 20. Pp. 6418-6432.

20. Ghadimi P., Kara S., Kornfeld B. The optimal selection of on-site CHP systems through integrated sizing and operational strategy. Applied Energy. 2014. Vol. 126. Pp. 38-46. 
21. Chen L., Xu F., Wang X., Min Y., Ding M., Huang P. Implementation and effect of thermal storage in improving wind power accommodation. Proceedings of the Chinese Society of Electrical Engineering. 2015. No 17. Pp. 4283-4290.

22. Steffen B., Weber C. Efficient storage capacity in power systems with thermal and renewable generation. Energy Economics. 2013. Vol. 36. Issue C. Pp. 556-567.

23. Ding T., Liu S., Yuan W., Bie Z., Zeng B. A two-stage robust reactive power optimization considering uncertain wind power integration in active distribution networks. IEEE Transactions on Sustainable Energy. 2016. No 1. Pp. 301-311.

УЗГОДЖЕНЕ ТА ОПТИМІЗОВАНЕ ВІДПРАВЛЕННЯ ДЖЕРЕЛ, НАВАНТАЖЕНЬ ТА НАКОПИЧЕННЯ ЕНЕРГІЇ В КОМБІНОВАНИХ ЕЛЕКТРИЧНИХ ТА ОПАЛЮВАЛЬНИХ СИСТЕМАХ, ЩО ВРАХОВУС НЕВИЗНАЧЕНІСТЬ ТА ВІДПОВІДЬ ПОПИТУ

\author{
Ruiqing Lian", Yiran You', Yong $\mathrm{Li}^{3}$, Shiwei $\mathrm{Su}^{1}$ \\ ${ }^{1}$ College of Electrical Engineering \& New Energy, China Three Gorges University, \\ Yichang 443002, China \\ ${ }^{2}$ Quanzhou Power Supply Company of State Grid Fujian Electric Power Co., Ltd., \\ Quanzhou 362000, China, $\quad$ E-mail: yyr937@foxmail.com \\ ${ }^{3}$ Dawu Power Supply Company of State Grid Hubei Electric Power Co., Ltd., \\ Dawu 432800, China
}

Обмеження вітроенергетики, викликані, головним чином, невизначеністю вітрової генерації $і$ пов'язаністю електричної і теплової потужності ТЕЦ є серйозною проблемою північних районів Китаю. 3 метою вирішення иієї проблеми в даній статті запропоновано модель оптимального управління виробництвом-споживаннямакумулюванням енергї̈ в об'єднаній електротепловій системі з метою мінімізації обмежень вітрової енергії $i$ загальних витрат на управління системою. Насамперед, регулюючі електричні та теплові навантаження споживачів розділено на три типи відповідно до їхнього призначення, а саме, на перекладні, пересувні та зменшувані і для кожної з них побудовано моделі відгуку задля підвищення точності оптимізації на стороні споживання. Потім для вирішення проблеми невизначеності вітроенергетики використано сиенарний метод. У ньому враховано вплив акумулювання енергіі на управління системою. Нарешті, ефективність запропонованої моделі для просування використання вітрової енергї та підвищення загальної економічної вигоди підтверджено на прикладах ї̈ використання. Бібл. 23, рис. 8, табл. 1.

Ключові слова: невизначеність вітроенергетики; оптимізація координації генерація-навантаження-сховище; оптимізоване планування; споживання вітрової енергії; відповідь на вимогу. 